\title{
Video Case: Endoscopic Extraction of a Large Piece of Fleshy Meat from the Esophagus by the Polypectomy Snare
}

\author{
Mohamed H Emara \\ Tropical Medicine Department, Faculty of Medicine, Zagazig University, Zagazig, \\ Egypt
}

\section{Comment}

A fifty five years old female presented with acute dysphasia of 5 hours duration following ingestion of a large piece of fleshy meat. The patient feel a sense of impacted lump at the lower end of the sternum associated with repeated attack of retching. When examined by flexible upper endoscopy under light sedation using intravenous diazepam $10 \mathrm{mg}$, a large white fleshy piece of meat was seen impacted at the lower end of the esophagus about $35 \mathrm{~cm}$ from incisors. Several trials to push the fleshy meat to inside the stomach failed. Then several trials for fragmentation using the biopsy forceps and Dormia basket failed to extract the meat, till finally it was grasped firmly with a polypectomy snare and extracted to outside without any further hazard to the patient. 